\title{
Simulation of energy use, human thermal comfort and office work performance in buildings with moderately drifting operative temperatures
}

Kolarik, Jakub; Toftum, Jørn; Olesen, Bjarne W.; Jensen, Kasper L.

Published in:

Energy and Buildings

Link to article, DOI:

10.1016/j.enbuild.2011.07.008

Publication date:

2011

Link back to DTU Orbit

Citation (APA):

Kolarik, J., Toftum, J., Olesen, B. W., \& Jensen, K. L. (2011). Simulation of energy use, human thermal comfort and office work performance in buildings with moderately drifting operative temperatures. Energy and Buildings, 43(11), 2988-2997. https://doi.org/10.1016/j.enbuild.2011.07.008

\section{General rights}

Copyright and moral rights for the publications made accessible in the public portal are retained by the authors and/or other copyright owners and it is a condition of accessing publications that users recognise and abide by the legal requirements associated with these rights.

- Users may download and print one copy of any publication from the public portal for the purpose of private study or research.

- You may not further distribute the material or use it for any profit-making activity or commercial gain

- You may freely distribute the URL identifying the publication in the public portal 


\title{
Simulation of Energy Use, Human Thermal Comfort and Office Work Performance in Buildings with Moderately Drifting Operative Temperatures
}

\author{
Jakub Kolarik $^{\mathrm{a}, *}$, Jørn Toftum ${ }^{\mathrm{a}}$, BjarneW. Olesen ${ }^{\mathrm{a}}$, Kasper L. Jensen ${ }^{\mathrm{b}}$ \\ ${ }^{a}$ International Centre for Indoor Environment and Energy, Department of Civil Engineering, Technical University \\ of Denmark, Nils Koppels Allé, DTU, Building 402, 2800 Kgs. Lyngby, Denmark \\ ${ }^{\mathrm{b}}$ Alectia A/S, Skanderborgvej 190, 8260 Viby J, Denmark \\ * Corresponding author: jakol@byg.dtu.dk
}

\begin{abstract}
Annual primary energy use in a central module of an office building consisting of two offices separated with a corridor was estimated by means of dynamic computer simulations. The simulations were conducted for conventional all-air VAV ventilation system and Thermo Active Building System (TABS) supplemented with CAV ventilation. Simulations comprised moderate, hot-dry and hot-humid climate. Heavy and light wall construction and two orientations of the building (east-west and north-south) were considered. Besides the energy use, also capability of examined systems to keep a certain level of thermal comfort was examined. The results showed that with the moderate climate, the TABS decreased the primary energy use by about $16 \%$ as compared with the VAV. With hothumid climate, the portion of the primary energy saved by TABS was ca. $50 \%$ even with the supply air dehumidification taken into account. The TABS working in a moderate climate kept the Predicted Percentage of Dissatisfied (PPD) $<10 \%$ during $60 \%$ to $80 \%$ of the working hours per year. Optimization of the TABS's control strategy (circulation pump dead-band, water supply temperature) resulted in significant reduction of the annual working hours with PPD>10\%; 1.4\% in comparison to $17.5 \%$ hours/year. The highest estimated loss of occupants’ productivity related to their thermal sensation hasn't exceeded $1 \%$ in whole year average.
\end{abstract}

\section{Introduction}

Current strategies for operation of buildings in developed countries often result in unsustainably high energy consumption. New types of climatic systems aim at low energy consumption and rely, for example, on a building's thermal mass in combination with night cooling/heating. Other systems provide cooling/heating by water circulated through pipes embedded in floors, walls or ceilings (Thermo Active Building System - TABS). Such systems may be associated with daily drifts of indoor temperatures, but accepting some variation of temperatures during the day 
rather than to keep them steady, which is common in most air-conditioned buildings, has been shown to be a feasible means to reduce the building energy demand [1,2].

TABS offer the possibility to reduce the energy demand both on the "system" and "room side". On the system side, separation of ventilation and thermal conditioning of the space allows the ventilation system to be designed according to the desired indoor air quality. Thermal loads are extracted by the activated building construction (ceiling, floor or even walls) by means of radiation and partly convection [3]. At the same time, the thermal mass of the building construction accumulates thermal energy, which helps to reduce peak loads and justifies smaller installed heating or cooling capacity or, in some cases, even eliminates the need for mechanical cooling. Another advantage is that the temperature of the cooling/heating medium may be kept close to the room temperature, which allows utilization of renewable energy sources - heat pumps, ground heat exchangers etc. [1]. On the room side, as a consequence of the heat accumulation, operation of the system does not keep a constant temperature, but may be associated with moderate drifts of indoor temperatures, also during the building occupancy period.

Recent research work by Kolarik et al. [4] has shown that moderate temperature ramps had no influence on the width of the comfort zone otherwise established under steady-state conditions [5], as long as the slope of the ramp was smaller than $\pm 4.4^{\circ} \mathrm{C} / \mathrm{h}$ and continuous exposure to the ramp was shorter than or equal to 4 hours. The study demonstrated that during continuous exposures lasting more than 4 hours, temperature ramps contributed to enhanced intensity of headaches and other general SBS symptoms. This is in agreement with results of previous studies showing that increasing indoor temperatures in buildings may be associated with increased intensity of symptoms of fatigue, headache and difficulty in thinking clearly [6]. Also, a field study by Mendell et al. [7] found significant effects of temperature on the prevalence of SBS symptoms, even within the temperature comfort zone. Therefore, taking into account results of previous research, elevated intensity of SBS symptoms may be expected to negatively affect the performance of occupants’ mental work. In the study by Kolarik et al. [4] increasing operative temperatures appeared to slightly decrease the speed of repetitive tasks that require mental efforts (addition and text typing). It has been shown that expenses incurred in employee salaries exceed building energy costs by a factor 100 and maintenance costs by a factor of 10 , and reduced energy consumption should therefore not be achieved at the expense of occupants' comfort, productivity or even health [8]. 
This paper summarizes results of computer simulations of energy consumption and indoor thermal environment of the building conditionned by means of the different HVAC systems: a commonly used all-air system and system involving activation of the building's thermal mass. The potential influence on office work performance of the thermal conditions resulting from using the selected systems was estimated.

\section{Methods}

The simulations, described in the present paper, were performed using the IDA Indoor Climate and Energy building simulation tool [9]. It allows simultaneous performance assessments of all building issues such as facade and wall construction, window glazing, HVAC systems, controls, indoor air quality, human thermal comfort and energy consumption.

\subsection{Building model}

The model used in all simulations included a central module of an office building with two offices separated by a corridor (Figure 1). Both the corridor and each of the offices were treated as separate zones. The selection of the building module was based on earlier work by Olesen and Dossi [2]. Thermal characteristics of the building components are given in Table 1.

(----Figure 1 should be located here----)

The building module was conditioned by three different systems - all-air variable volume system and thermo active building system with two different water pump operation schedules. Two types of wall construction (both internal and external walls) were examined. The heavy $\left(320 \mathrm{~kJ} / \mathrm{m}^{2}\right)$ construction was designed to have a higher thermal mass, while the light $\left(14 \mathrm{~kJ} / \mathrm{m}^{2}\right)$ construction consisted only of a steel frame and thermal insulation. Two orientations of the building module were examined - with windows facing east-west and north-south. All spaces adjacent to the central module were assumed to have the same internal temperatures as the test space, wherefore only heat transmission through external walls was considered.

\subsection{Locations and meteorological data}

Simulations were performed for three locations in the USA, each representing a different climate: San Francisco, Miami and Phoenix (Table 2). Typical Meteorological Year Version 2 (TMY2) [10] was used as climate data input. TMY2 was produced using an objective statistical algorithm to select the most typical month from long-term 
meteorological observations. The duration of cooling/heating period for each particular location was established using monthly average outdoor temperatures $\left(\theta_{m, \text { aver }}\right)$; Table 2 .

(----Table 1 should be located here----)

(----Table 2 should be located here----)

(-----Table 3 should be located here----)

Total internal heat load in the office zones was considered approx. $630 \mathrm{~W} / \mathrm{zone}\left(32 \mathrm{~W} / \mathrm{m}^{2}\right)$. The load included heat production by two occupants, present in the building during week days from $8^{00}$ to $12^{00}$ and from $13^{00}$ to $17^{00}$. Occupants' metabolic rate was considered to be approx. 1.2 met; that corresponds to about $238 \mathrm{~W}$ [13]. Office equipment (two computers and printer) were estimated to produce $350 \mathrm{~W}$ (long wave radiation fraction 50\%) and ceiling light $50 \mathrm{~W}$ (convective fraction 50\%) of heat. Heat loads from equipment and light had the same time schedule as occupants as it could be assumed that people switched off the light and their computers during the lunch break. Moisture production by occupants was taken into account in the zone model, calculation of the moisture load was done according to EN ISO Standard 7730 [13]. In addition, there was $100 \mathrm{~W}$ ceiling light as the only heat source in the corridor zone.

The windows in the office zones were equipped with two types of solar shading devices. When the solar radiation incident on an inside glass pane exceeded $100 \mathrm{~W} / \mathrm{m}^{2}$, an external window shading screen in dimmensions $0.9 \times 3 \mathrm{~m}$ shaded the upper part of the window. Further increase of the solar heat gain above $200 \mathrm{~W} / \mathrm{m}^{2}$ activated internal blinds. When the internal blinds were drawn, the total shading coefficient of the window was multiplied by a factor of 0.65 and the short-wave shading coefficient of the window by a factor of 0.16 . No effect of the internal blinds on the U-value of the window was considered. Both types of solar shading devices had simple two position (on/off) control.

\subsection{Description of the simulated climatic systems}

a) Corridor: CAV system (operation: weekdays; $6^{00}-18^{00}$ ); outdoor air change rate: $0.5 \mathrm{ACH}(3.4 \mathrm{~L} / \mathrm{s}$ ); supplied air temperature: $19^{\circ} \mathrm{C}$; supply/exhaust airflow ratio: 1 .

b) Office zones - all-air ventilation (further abbreviated as VAV): VAV system with heat recovery (operation: weekdays $7^{00}-18^{00}$; Sundays $8^{00}-24^{00}$ ); maximum possible airflow: $16 \mathrm{~L} / \mathrm{s} \mathrm{m}{ }^{2}-10 \mathrm{ACH} /$ zone (for Phoenix increased 
to $30 \mathrm{~L} / \mathrm{s} \mathrm{m}^{2}-19 \mathrm{ACH} /$ zone); minimum supply airflow: $2 \mathrm{~L} / \mathrm{s} \mathrm{m}^{2}$ (39.6 L/s) (to keep acceptable indoor air quality [14]); on Sundays $70 \%$ of the required airflow was used; temperature of the supplied air: $19{ }^{\circ} \mathrm{C}$; zone temperature set-point: $24.5 \pm 1.5^{\circ} \mathrm{C}$ (cooling period ), $22 \pm 2^{\circ} \mathrm{C}$ (heating period).

c) Office zones - thermo active building system (abbreviated as TABS): Ceiling/floor concrete core conditioning was complemented with a CAV ventilation system with heat recovery (operation: weekdays $8^{00}-12^{00}$ and $13^{00}-17^{00}$ ); supply airflow: $2 \mathrm{~L} / \mathrm{sm}^{2}$ (39.6 L/s) (to keep acceptable indoor air quality [14]); temperature of the supplied air: $19^{\circ} \mathrm{C}$; water circulation pump operation: $24 \mathrm{~h} /$ day with $22-23^{\circ} \mathrm{C}$ dead-band; water mass flow rate $350 \mathrm{~kg} / \mathrm{h}$; inlet water temperature $\left(\theta_{s}\right)$ control: according to equation (1) established by Olesen and Dossi [2].

$$
\theta_{s}=0,52 \times\left(20-\theta_{e}\right)+20-1,6 \times\left(\theta_{o}-22\right),\left[{ }^{\circ} C\right]
$$

where $\theta_{e}$ is ambient air temperature $\left[{ }^{\circ} \mathrm{C}\right], \theta_{o}$ operative temperature in the reference zone $\left[{ }^{\circ} \mathrm{C}\right]$. The inlet water temperature was limited to the zone dew point temperature (absolute minimum was set to $22^{\circ} \mathrm{C}$ ).

d) Office zones - thermo active building system (further abbreviated as TABSn) system with night operation: the same as c) but the water circulation pump worked only during the night (weekdays; $17^{00}-8^{00}$ ).

\subsection{Analysis of the results}

\subsubsection{Analysis of the energy use}

The amount of the energy used to condition the indoor climate in the building module was determined and compared for all simulated HVAC systems. In the analysis, energy (kWh) delivered to a particular HVAC system, was divided into the following parts: 1 / zone heating/cooling - thermal energy supplied to the activated building construction (pipes embedded in floor/ceiling slab); 2/ AHU heating/cooling - thermal energy supplied to heating/cooling coils in air handling units to condition the air supplied to the zones; $3 /$ thermal energy recovered in the air to air heat exchanger; 4/ electricity - direct electricity consumed by fans, pumps, equipment and lighting in the zones. The annual energy use per square meter of the space $\left(\mathrm{kWh} / \mathrm{m}^{2}\right.$ yr) was calculated for all elements (from1/ to $4 /$ ) of the energy use divided as presented above. To estimate an annual use of primary energy, several assumptions regarding the energy generation/transformation had to be made. It was assumed that hot and cold water for coils in the air handling unit was provided by a gas boiler and a compressor cooling unit, respectively. The activated building construction utilized a ground heat exchanger during cooling period and gas boiler during heating period. Table 3 
lists assumed thermal efficiencies for later energy transformation components, the table also gives values of primary energy factors necessary to describe the primary energy transformation. In the case of ground heat exchanger the primary energy factor was set to zero - the only energy transformed from primary sources consumed by thermo active system was an auxiliary power - electricity for circulation pumps. Percentual decrease of the primary energy consumption in the case of use of the TABS systems in the comparison to the base case system (VAV), $\Delta E_{\text {prim }}$, was calculated according to the equation (2). It illustrates the potential of each simulated system to decrease the primary energy use in comparison to the base case.

$$
\Delta E_{p r i m}=\left(1-\frac{E_{p r i m, S}}{E_{p r i m, V A V}}\right) \cdot 100,[\%]
$$

where $E_{\text {prim }, S}$ is annual primary energy consumption of the particular system $\left[\mathrm{kWh} / \mathrm{m}^{2} \mathrm{yr}\right]$ and $E_{\text {prim }, V A V}$ is annual primary energy consumption of the base case system $\left[\mathrm{kWh} / \mathrm{m}^{2} \mathrm{yr}\right]$.

\subsubsection{Thermal comfort criteria}

Hourly values of the PMV and PPD indices [13] were calculated by the simulation software based on air temperature, mean radiant temperature, air humidity and air velocity in the office zones and with fixed values of clothing insulation and metabolic heat production (had to be set prior to the simulation). Clothing insulation was set to 0.5 clo for simulations corresponding to the cooling period and to 1 clo during the heating period (for specification of heating/cooling periods see Table 2). This approach is based on ASHRAE Standard 55 [5]. The metabolic heat production was set to 1.2 met (light sedentary work) in all simulations.

Long term evaluation of the thermal comfort conditions was conducted to determine the ability of the simulated systems to keep the comfort limits specified by current standards (Table 4). The percentage of time when the temperature was outside the range defined by the comfort limits was determined for all the simulated cases. The comfort limits of $90 \%$ and $85 \%$ of thermally satisfied occupants, corresponding with category B and category C in ISO standard 7730 [13] were taken into account by using the PPD index to determine the percentage of discomfort periods (PPD>10\%; PPD>15\%). Category B requirements conform to those specified in ASHRAE Standard 55 [5]. In addition, duration diagrams for the PMV index and the operative temperature during working hours were analysed. The simulated building module included two office zones. However, the thermal comfort conditions were 
evaluated only for one reference zone, which was chosen as the zone in which the highest external heat loads were expected to occur during the day. The intensity of external heat loads depended on the solar radiation and consequently on the orientation of the building (east-west or north-south). Taking into consideration both the tested orientations, the following reference zones were used: 1 / zone with window facing west for building oriented east west; 2/ zone with window facing south for building oriented north-south.

(----Table 4 should be located here----)

\subsubsection{Daily average temperature drift}

The daily average temperature drift that would be experienced by occupants of a building during one work day was calculated from the following equation:

$$
\bar{r}[K / h]=\frac{\sum_{i=1}^{n-1}\left|\theta_{o, i+1}-\theta_{o, i}\right|}{n-1}
$$

where $\theta_{o}$ is operative temperature of the zone $\left[{ }^{\circ} \mathrm{C}\right], i$ is an ordinal number of the hours during the period of occupancy [-] and $n$ is the number of hours during which the building is occupied (n=8) [ - ].

\subsubsection{Direction of the temperature drift}

The direction of the temperature drifts during each simulated workday was determined and analyzed. Output from the simulation software provided operative temperatures in the zone in one hour time-steps. The direction of the temperature drift was determined by calculating the difference between two operative temperatures for adjacent hours (time steps). In this way seven values of temperature differences were obtained. Negative temperature difference indicated a decreasing temperature drift. The percent of negative differences during each simulated day was then determined.

\subsection{Estimated influence on occupants’ performance}

Jensen et al. [15] describes a method to evaluate the effects of temperature on occupants' performance during a year in a mechanically ventilated building. It can be used to compare different building designs in order to evaluate the best performing design according to total economy (cost of investment, energy cost and productivity of the occupants). The method builds among other elements on the data used as the platform of the ASHRAE adaptive thermal comfort model [16]. These data combined with a bayesian network model enables estimation of individual 
differences in how people are affected by the thermal environment even though they are exposed to identical conditions. Using the hourly temperature output from the simulations, the performance model of Jensen et al. [15] was used to calculate a yearly performance index (PI), which describes the relative loss of performance. The PI describes the time-weighted performance of office employees in a given building design alternative and the ensuing thermal environment during the considered period. Due to inter-individual differences in how people's performance are affected by the thermal environment it is not possible to achieve a performance index of 100; this can only be achieved by using individually controlled systems. The PI was compared for six cases representing the worst comfort conditions that resulted from the operation of the simulated HVAC systems.

\subsection{Adaptation of the control algorithm}

As the building-system interaction plays a significant role in the case of application of TABS [17, 18], it is common that the system needs further tunning of the control strategy to achieve a match between the operation of the building and system's performance. Such adaptation of the control algorithm for the TABS system was applied on one of the simulated cases: building module with heavy walls oriented east-west and situated in San Francisco. The Table 5 summarizes the changes made on the parameters of the model to adapt the control algorithm. All remaining parameters of the model were kept the same as in the previous simulations.

(----Table 5 should be located here----)

(----Table 6 should be located here----)

\section{Results}

\subsection{Energy use}

The annual energy use of the simulated building module for simulated locations, types of wall construction and building orientation is summarized in Table 6. The estimated annual primary energy use for all simulated cases is presented in Table 7.

(----Table 7 should be located here----)

The lowest energy use was observed in San Francisco with a moderate climate. At this location, utilization of thermo active building systems (TABS and TABSn) decreased the primary energy use about $16 \%$ in comparison with the VAV system (base case). Neither building orientation nor wall construction affected the primary energy use 
by more than 5\% among all cases simulated in San Francisco. The energy use of all-air system in Phoenix was higher than for San Francisco, but at the same time it was lower than for Miami. Compared with the VAV system, utilization of systems involving thermal mass activation (TABS and TABSn) decreased the primary energy use by ca. 50\% regardless of the orientation or building construction type. In Phoenix, north-south orientation resulted in slightly lower energy use for all cases, but the difference exceeded 5\% only with the VAV system (both heavy and light construction). The difference caused by the wall construction did not exceed $5 \%$ in any case. The building located in Miami had the highest energy consumption of all the simulated locations. Utilization of thermal mass activation (TABS and TABSn) decreased the primary energy use by about $50 \%$ as compared with the VAV system, regardless of the orientation or building construction. The difference between heavy and light wall construction was less than $5 \%$ in all cases and thus the effect of orientation and wall construction on primary energy use was negligible. Taking into consideration all simulated cases, neither the building orientation nor the type of wall construction affected the primary energy use by more than $15 \%$.

In San Francisco, the primary energy used by the fans corresponded to ca. $27 \%$ of the total primary energy use with the VAV system and 10\% for TABS/TABSn in all cases. In Phoenix and Miami the primary energy used by the fans with the VAV system corresponded to about $20 \%$ and $15 \%$ of the total primary energy use of the building module respectively. At these locations, the fans used between $7 \%$ to $9 \%$ of the total primary energy use with TABS/TABSn systems. The primary energy used by the pumps was below $3 \%$ of the total primary energy use for the VAV system, while for TABS it was ca. 13\% of the total primary energy use and for TABSn about $10 \%$.

\subsubsection{Primary energy use of the TABS after the adaptation of the control algorithm}

Comparing the primary energy use of the TABS before and after the adaptation of the control algorithm (see Table 5), the highest difference $-5 \mathrm{kWh} / \mathrm{m}^{2} \mathrm{yr}$ was observed for the energy used by circulation pumps. This implies that the adaptation of the control algorithm resulted in reduction of the pump/system operation time, which consequently resulted also in lower total primary energy use; from 195 to $176 \mathrm{kWh} / \mathrm{m}^{2} \mathrm{a}(10 \%)$.

\subsection{Indoor climate conditions}

Table 8 summarizes the prevalence of working hours per year during which the comfort limits were exceeded. The comfort limits, corresponding with the ISO standard (ISO 2005), were defined considering $90 \%$ and $85 \%$ of thermally satisfied occupants (PPD $<10 \%$ - category B and PPD $<15 \%$ - category C). 
In San Francisco, the VAV system kept the requirements of category B during more than $95 \%$ of the working hours during the whole year, regardless of the orientation and type of wall construction. The systems involving thermal mass activation (TABS and TABSn) were able to keep category B requirements during from $82 \%$ to $60 \%$ of the working hours during per year. The light wall construction was associated with about $15 \%$ more hours with exceeded comfort limits when compared to heavy walls. Change of the orientation from east-west to north-south led to about $8 \%$ more working hours per year outside the comfort range.

Figure 2 shows the duration diagram of operative temperature in the southern zone of the building with heavy and light construction oriented north-south in San Francisco (north-south orientation resulted in higher prevalence of discomfort - see Table 8).

(----Table 8 should be located here----)

The figure shows the effect of wall construction on the temperature development with thermo active systems. The effect of wall construction seems to be stronger than the effect of operation time of the water supply pump (TABS, TABSn). Utilization of thermo active systems during the heating period led to operative temperatures higher than $24^{\circ} \mathrm{C}$ during about $40 \%$ of the working hours.

(----Figure 2 should be located here----)

In Phoenix, the VAV system managed to keep the indoor climate conditions within the category B comfort limits during more than $95 \%$ of the working hours per year. Thermo active building systems (TABS and TABSn) were able to keep category B requirements during about $77 \%$ of the working hours per year. With latter systems, the light wall construction resulted, as compared with heavy walls, in slightly higher (about 6\%) percentage of hours with temperatures beyond the comfort range, while the prevalence of such hours decreased with a change of the orientation from east-west to north-south by 5\%. In Miami, the percentage of working hours when the category B requirements were exceeded was not higher than $6 \%$.

With more relaxed comfort limits (category C), all systems were able to keep the requirements in San Francisco during at least $80 \%$ of the working hours per year. The VAV system kept category C requirements during more than $96 \%$ of the working hours, and similar results were observed with thermo active systems (TABS and TABSn) with heavy wall construction. In Phoenix only thermo active (TABS and TABSn) systems with light wall construction 
were able to keep the category C requirements during less than $95 \%$ of working hours a year. In Miami, category C requirements were kept with all systems during more than 95\% of working hours.

\subsubsection{Indoor climate conditions after the adaptation of the control algorithm}

Figure 3 shows the results obtained with the adapted the control algorithm. The prevalence of the working hours with conditions outside particular comfort limits decreased in the case of the system with adapted control algorithm (TABSa).

(----Figure 3 should be located here----)

\subsection{Occupant performance}

Table 9 shows a comparison of six different cases which estimates the effects on the annual occupant performance of the thermal conditions has been made. The results indicate that there is only modest difference in the occupant performance between the six different designs when using data from a whole year as input to the performance estimation. Some systems had difficulties in fulfilling the thermal comfort demands, being either too cold or too warm during some hours of the year, but generally the temperature distribution lies within the preferred temperature range for optimal occupant performance.

(----Table 9 should be located here----)

\subsection{Daily operative temperature drifts}

Operation of the variable air volume system was associated only with very modest temperature drifts; the rate of temperature change was mostly less than $0.1 \mathrm{~K} / \mathrm{h}$ or fell into the $0.1-0.3 \mathrm{~K} / \mathrm{h}$ interval regardless of the wall construction, building orientation or even location. Operation of thermo active-systems (TABS and TABSn) in a building with heavy wall construction resulted mostly in drifts within the $0.1-0.3 \mathrm{~K} / \mathrm{h}$ interval. Utilization of a light wall construction shifted the interval of the most often occurring drifts towards higher rates of temperature change; 0.3-0.5 K/h and 0.5-0.7 K/h. An example of such a shift in the rate of temperature change can be seen in Figure 4 . Occupants in the simulated building module would be mostly exposed to increasing operative temperature. The decreasing temperature appeared mostly once or twice out of seven possible temperature differences calculated between adjacent hours during a working day. That was associated mainly with a lunch break, when internal heat loads in the zone were lowered. 
(----Figure 4 should be located here----)

\subsection{Relation between primary energy use and thermal comfort}

Table 10 shows the comparison of the percentual decrease of the primary energy consumption when TABS system was used in comparison to the VAV system together with the percentage of working hours outside comfort categories B and C according to EN ISO 7730 [13]. In moderate climate (San Francisco) utilization of thermo active building system only slightly decreased the primary energy use, while its operation resulted in indoor climate conditions being up to $6.7 \%$ (light walls) of working hours per year outside the category C. Operation of thermo active building system in hot-dry climate (Phoenix) resulted in conditions outside category C for up to 5.7\% (light walls) of working hours per year, but the system demanded about 50\% less primary energy than the VAV system. In hot-humid climate (Miami) thermo active building system was able to keep category C conditions for almost all working hours with approx. 50\% lower primary energy use when compared to VAV.

(----Table 10 should be located here----)

\section{Discussion}

As expected, the energy demand of each simulated system differed markedly among the tested locations. Application of a system involving thermal mass activation combined with constant volume ventilation decreased both thermal and primary energy use in all locations. This energy saving effect was lowest in case of the moderate climate (San Francisco). This was probably caused by the fact that outdoor temperatures in San Francisco were quite often close to the supply air temperature $\left(19^{\circ} \mathrm{C}\right)$, this way the VAV system was able to extract heat loads with ventilation air without eminent need for mechanical cooling. On the other side, thermo active system extracted the same loads mainly by means of activated floor/ceiling surface, which required remarkable amount of pump power.

North-south orientation of the building generally decreased the energy use, but the east-west to north-south difference was not higher than 15\%. The type of building construction appeared to have a stronger effect on the thermal comfort conditions than on the energy demand. The data in Table 8 indicate that a light building construction clearly contributed to a higher number of working hours with conditions outside comfort limits when the thermo active building system was used in San Francisco and Phoenix. In these locations the prevalence of working hours outside comfort was more pronounced during the heating season. 
It is clear from the Table 8 that the utilization of the TABS had the strongest positive effect in the case of its operation in Miami (hot-humid climate). However, the original simulation did not take into account the relative humidity levels in the room. Further analysis of the data showed that while for San Francisco the relative humidity was between 30 and 50\% and for Phoenix it was between 20 and 60\%, in Miami the relative humidity indoors was higher than $70 \%$ during $33 \%$ of the working hours both for the VAV and the thermo active systems. Although the relative humidity does not have a strong impact on thermal comfort in the comfortable range of temperatures, it is known that it may negatively affect the perceived air quality [6]. Moreover, high relative humidity indoors means an increasing risk of mould growth, which can be associated with serious health problems [20]. According to the current standards indoor relative humidity should be within the range $30-50 \%$ [13, 19]. The latter indicates that dehumidification may be needed in the case of Miami. Further simulations were done to estimate the change in the primary energy consumption due to the dehumidification in the hot-humid climate zone. A simple dehumidification strategy was applied using combination of a cooling-coil and secondary heating-coil in the air handling unit. Figure 5 shows the results of the latter simulations. Dehumidification clearly reduced the relative humidity in the building (Figure 5a), but, as it was expected, increased the primary energy consumption. Although the primary energy consumption increased both in the case of the VAV and the TABS system, Figure 5b clearly illustrates the advantage of the thermo active system. Dehumidification increased the primary energy consumption in the building with the TABS by $6 \%$ while in the case of the VAV it was $37 \%$.

(----Figure 5 should be located here----)

The European standard EN 15251 [19] suggests a methodology for long-term evaluation of the indoor environment. The standard accepts that indoor conditions can be outside the comfort range during 3-5\% of the working hours per year. Taking into account upper limit later range - 5\% of the working hours per year outside the category II (normal level of expectation, $\mathrm{PPD}<10 \%$, correspond to the category B in EN ISO 7730 [13]), the simulated VAV system would meet the requirements in all cases. Thermo active systems would meet the requirements only with a heavy building construction situated in a hot and humid climate (Miami) while the indoor environment in a light building construction at the same location would be very close to the requirements. Operation of the thermo active systems at the remaining locations would lead to a higher prevalence of working hours outside the comfort range than recommended by the standard. However, extension of the discomfort periods was caused rather by deficient optimization of system parameters than by insufficient capacity of the thermo active systems. This suggests that 
while the cooling/heating capacity wof the TABS system was sufficient, the control algorithm required some adaptation. Such adaptation of the system's operation-control algorithm was done to decrease the prevalence of working hours outside the comfort range. The simple adaptation including modification of the circulation pump dead-band and a change of minimal temperature of water supplied to the activated construction (see Table 5) resulted in significant reduction of the annual working hours with PPD >10\%: $1.4 \%$ in comparison to $17.5 \%$ hours/year for moderate climate.

Analysis of the average yearly performance decrement showed that all simulated systems were able to provide appropriate conditions without negatively affecting occupants' performance. Kolarik et al. [4] also showed that occupant performance was not negatively affected by temperature ramps of this rate when continuous exposure did not exceed four hours.

The study confirmed findings of previous research and showed that thermo active building systems are capable of providing comfortable indoor climate conditions with lower energy consumption [21, 2]. At the same time, results of the simulations imply that the applicability of the thermo active system depends on the climatic conditions and the chosen operation strategy. It should be noted that the operation strategy used in the present study was a simple outdoor temperature-inside operative temperature compensated water temperature control. The switching of the heating/cooling operation mode was based on fixed rules deffining relations between the zone operative temperature and outdoor temperature (see Table 5). Recently, Gwerder et al. [22, 23] introduced advanced method for the control of thermoactive systems, which offers more integral approach to the complex problem of controlling systems envolving high thermal mass. Utilization of such methods can significantly reduce the need for further adaptaion of the control algoritms. The present study, together with above mentionned publications implies, that the decision to utilize the thermoactive system should be accompanied with a proper analysis of its performance (energy demand and achievable comfort conditions) for given combination of a climate and building construction. This analysis could be based on dynamic computer simulation, which can account for the dynamic behaviour of the systembuilding interaction.

\section{Conclusions}

- Application of the TABS system decreased the primary energy use by ca. $50 \%$, as compared with a VAV system, in case of hot-humid and hot-dry climates. 
- With the VAV system, mean daily temperature drifts were mostly below $0.1 \mathrm{~K} / \mathrm{h}$, whereas thermo active building systems were mostly associated with drifts ranging from $0.3 \mathrm{~K} / \mathrm{h}$ to $0.5 \mathrm{~K} / \mathrm{h}$. A light wall construction of the building was also associated with higher prevalence of higher mean daily operative temperature drifts, up to $0.7 \mathrm{~K} / \mathrm{h}$. Rates of change of temperature above $2.4 \mathrm{~K} / \mathrm{h}$ was not observed in any case.

- Operation of TABS in moderate and hot-dry climates resulted in exceedence of the limit of $90 \%$ thermally satisfied occupants (PPD $<10 \%$ ) during $16 \%$ to $40 \%$ of the working hours/year (depending on the building orientation and wall construction). However, the limit of $85 \%$ thermally satisfied occupants (PPD<15\%) was exceeded during more than $5 \%$ of the working hours only with a light wall construction and did not exceed $16 \%$ of the working hours in any case.

- Consequent optimization of the TABS's control strategy for moderate climate resulted in significant reduction of the annual working hours with PPD >10\%: 1.4\% in comparison to $17.5 \%$ hours/year.

- Regardless of the building orientation, a light wall construction caused a higher prevalence of discomfort periods when a thermo active building system was operated in moderate and hot-dry conditions.

- Despite the difference in ability to keep the requirements for thermal comfort, operation of all simulated systems hasn’t caused significant decrement of occupants’ performance.

- Change of the building orientation from east-west to north-south affected the primary energy use by less than $10 \%$ in all tested locations.

\section{Acknowledgements}

The research work was funded by ASHRAE Research Project 1269-RP, “Occupant Responses and Energy Use in Buildings with Moderately Drifting Temperatures” and the Danish Technical Research Council (STVF) as part of the research program of the International Centre for Indoor Environment and Energy at the Technical University of Denmark. The principal author was additionally supported by a scholarship from the International Visegrad Fund, Bratislava, Slovak Republic for the period 2005-2006 and by a research grant from the Polish Ministry of Higher Education for the period 2007-2008. 


\section{References}

[1] Meierhans, R.A. 1993. Slab cooling and earth coupling, ASHRAE Transactions 99:2, American Society of Heating, Refrigerating and Air Conditioning Engineers, Atlanta, USA.

[2] Olesen, B.W., Dossi, F.C. 2004. Operation and Control of Activated Slab Heating and Cooling Systems, CIB World Building Congress.

[3] REHVA 2007. Low Temperature Heating and High Temperature Cooling - Rehva Guidebook, ISBN 2-96004686-2, Federation of European Heating and Air-conditioning Associations, Brussels, Belgium.

[4] Kolarik, J., Toftum, J., Olesen, B.W., Shitzer, A. 2009. Thermal comfort and office work performance in environments with moderately drifting operative temperatures (1269-RP). H V A C \& R Research, Vol: 15(5), p. 931. American Society of Heating, Refrigerating and Air-Conditioning Engineers, Atlanta, USA.

[5] ASHRAE Standard 55-2004. 2004. Thermal environmental conditions for human occupancy, American Society of Heating, Refrigerating and Air Conditioning Engineers, Atlanta, USA.

[6] Fang, L., Clausen, G., Fanger, P.O. 1998. Impact of temperature and humidity on the perception of indoor air quality, Indoor Air, 8(2), pp. 80-90.

[7] Mendell, M.J., Fisk, W.J., Dong, M.X., et al. 1999. Enhanced particle filtration in a non-problem office environment: Preliminary results from a double-blind crossover intervention study, American Journal of Industrial Medicine Supplement 1:55-57.

[8] Clements-Croome, D. (ed) 2006. Creating the Productive Workplace, E\&FN Spon, Taylor \& Francis Group, London/New York, Second edition.

[9] Voulle, M. and Sahlin, P. 2000. IDA indoor climate and energy - a new generation simulation tool, Proceedings of Healthy Buildings, Vol. 2:523-528. Espoo, Finland.

[10] NREL - National Renewable Energy Laboratory. 1995. User's Manual for TMY2s (Typical Meteorological Years), NREL/SP-463-7668, and TMY2s, Golden, Cl, USA.

[11] ASHRAE 2001. ASHRAE Handbook - Fundamentals, American Society of Heating, Refrigerating and Air Conditioning Engineers, Atlanta, USA.

[12] EN 15603:2008. 2008. Energy performance of buildings - Overall energy use and definition of energy ratings, European Committee for Standardization, Brussels, Belgium.

[13] EN ISO 7730:2005. 2005. International standard: Ergonomics of the Thermal Environment-Analytical Determination of Thermal Comfort by Using Calculations of the PMV and PPD Indices and Local Thermal Comfort Criteria, International Standard Organization for Standardization, Geneva, Switzerland.

[14] CEN Report 1752. 1998. CEN Report: Ventilation for buildings. Design criteria for the indoor environment, CEN/TC 156/WG 6, European Committee for Standardization, Brussels, Belgium.

[15] K.L. Jensen, J. Toftum, P. Friis-Hansen, A Bayesian Network approach to the evaluation of building design and its consequences for employee performance and operational costs, Building and Environment, Vol.: 44 (3), 456-462, DOI: 10.1016/j.buildenv.2008.04.008

[16] de Dear, R.J. 1998. A global database of thermal comfort field experiments, ASHRAE Transactions 104 (1b) pp. 1141-1152, American Society of Heating, Refrigerating and Air Conditioning Engineers, Atlanta, USA.

[17] Meierhans, R. 1996. Room-air conditioning by means of overnight cooling of the concrete ceiling. ASHRAE Transactions Vol.: 102 (1), p. 693-697. American Society of Heating, Refrigerating and Air-Conditioning Engineers, Atlanta, USA.

[18] Olesen, B.W. Radiant floor-heating in theory and practice. ASHRAE Journal, July 2002, p. 19-26. American Society of Heating, Refrigerating and Air-Conditioning Engineers, Atlanta, USA. 
[19] EN 15251:2007. 2007. Indoor environmental input parameters for design and assessment of energy performance of buildings addressing indoor air quality, thermal environment, lighting and acoustics, European Committee for Standardization, Brussels, Belgium.

[20] Bornehag, C.G., et al. 2001. Dampness in Buildings and Health, Indoor Air 11(2), pp. 72-86.

[21] Hauser, G., Kempkes, C., Olesen, B.W. 2000. Computer Simulation of Hydronic Heating/Cooling System with Embedded Pipes. ASHRAE Handbook Transactions Symposia, Atlanta, USA.

[22] Gwerder, M., Lehmann, B., Tödtli, J., Dorer, V. and Renggli, F. 2008. Control of thermally-activated builidng systems (TABS). Applied Energy Vol. 85, p. 565-581.

[23] Gwerder, M., Tödtli, J., Lehmann, B., Dorer, V., Güntensperger, W. and Renggli, F. 2009. Control of thermally-activated builidng systems (TABS) in intermittent operation with pulse width modulation. Applied Energy Vol. 86, p. 1606-1616. 